\title{
RNA sequencing reveals retinal transcriptome changes in STZ-induced diabetic rats
}

\author{
YUAN-JIE LIU ${ }^{1}$, ZHI-YUN LIAN ${ }^{2}$, GENG LIU ${ }^{1}$, HONG-YING ZHOU ${ }^{1}$ and HUI-JUN YANG ${ }^{1}$ \\ ${ }^{1}$ Department of Human Anatomy, West China School of Preclinical and Forensic Medicine, Sichuan University; \\ ${ }^{2}$ Department of Neurology, West China Hospital of Sichuan University, Chengdu, Sichuan 610041, P.R. China
}

Received March 2, 2015; Accepted December 11, 2015

DOI: $10.3892 / \mathrm{mmr} .2016 .4793$

\begin{abstract}
The present study aimed to investigate changes in retinal gene expression in streptozotocin (STZ)-induced diabetic rats using next-generation sequencing, utilize transcriptome signatures to investigate the molecular mechanisms of diabetic retinopathy (DR), and identify novel strategies for the treatment of DR. Diabetes was chemically induced in 10-week-old male Sprague-Dawley rats using STZ. Flash-electroretinography (F-ERG) was performed to evaluate the visual function of the rats. The retinas of the rats were removed to perform high throughput RNA sequence (RNA-seq) analysis. The a-wave, b-wave, oscillatory potential 1 (OP1), OP2 and $\Sigma$ OP amplitudes were significantly reduced in the diabetic group, compared with those of the control group $(\mathrm{P}<0.05)$. Furthermore, the implicit b-wave duration 16 weeks post-STZ induction were significantly longer in the diabetic rats, compared with the control rats $(\mathrm{P}<0.001)$. A total of 868 genes were identified, of which 565 were upregulated and 303 were downregulated. Among the differentially expressed genes (DEGs), 94 apoptotic genes and apoptosis regulatory genes, and 19 inflammatory genes were detected. The results of the KEGG pathway significant enrichment analysis revealed enrichment in cell adhesion molecules, complement and coagulation cascades, and antigen processing and presentation. Diabetes alters several transcripts in the retina, and RNA-seq provides novel insights into the molecular mechanisms underlying DR.
\end{abstract}

\section{Introduction}

Diabetic retinopathy (DR) is a major complication of diabetes mellitus and one of the leading causes of blindness in

Correspondence to: Professor Hui-Jun Yang, Department of Human Anatomy, West China School of Preclinical and Forensic Medicine, Sichuan University, 3-17 Renmin South Road, Chengdu, Sichuan 610041, P.R. China

E-mail: he500209@163.com

Key words: diabetic retinopathy, RNA-sequence, differentially expressed genes working-age adults (1). The disease is characterized and diagnosed by visual fundus examination to reveal vascular lesions and macular edema (2). Abundant data suggests that diabetes affects the entire neurovascular unit of the retina, with early loss of neurovascular coupling, gradual neurodegeneration, gliosis and neuroinflammation occurring prior to observable vascular pathologies $(3,4)$. The treatment of DR can only be achieved through an enhanced understanding of the pathogenesis of the disease. However, DR is a multifactorial progressive disease of the retina, and the pathogenesis of the disease is complex, involving several different cells, molecules and factors. Despite several investigations attempting to identify the molecular mechanisms of pathogenesis in DR, they remain to be fully elucidated.

Streptozotocin (STZ)-induced diabetes in rats is the most commonly used experimental model for the investigation of DR. This model mimics human diabetes through the destruction of b-cells in the pancreas, which leads to hypoinsulinemia and hyperglycemia (5).

Next-generation sequencing based on RNA sequence (RNA-seq) technology is predominantly used for quantitative gene expression analyses of biological processes in a particular tissue or cell in a certain species. RNA-seq can be used to investigate genome-wide differences in gene expression and information analysis platforms. This process has several advantages, including more accurate quantization, higher repeatability, wider testing range and more reliable analyses. Thus, RNA-seq has the potential to provide useful and detailed information on the mechanisms, unknown pathways and networks of a disease, and may lead to the identification of novel treatment strategies (6).

The purpose of the present study was to use RNA-seq to investigate the molecular mechanisms of DR within the retinas of STZ-induced diabetic rats. The results of this investigation may reveal novel avenues of investigation into treatment strategies for DR.

\section{Materials and methods}

STZ-induced diabetes in rats. Diabetes was chemically induced in 10-week-old male Sprague-Dawley rats $(n=30$; weight, 230-280 g; Chengdu DaShuo Biotech Co., Ltd. Chengdu, China) with STZ (Sigma-Aldrich, St. Louis, MO, USA). The rats received a single intraperitoneal injection of 
a freshly prepared solution of STZ in citrate buffer $(0.01 \mathrm{M}$; pH 4.5; Junrui Biological Technology Co., Ltd., Shanghai, China) at a dose of $60 \mathrm{mg} / \mathrm{kg}$ bodyweight. A corresponding number of weight and age-matched animals $(n=30)$ were maintained as controls, and these rats received a single intraperitoneal injection of citrate buffer only, at a dose of $60 \mathrm{mg} / \mathrm{kg}$ bodyweight. The diabetic status of the animals was confirmed by measuring the blood glucose levels of the rats using a glucometer (ACCU-CHEK ${ }^{\circledR}$ Performa; Roche Diagnostics GmbH, Mannheim, Germany), with fasting blood glucose levels $>16.7 \mathrm{mmol} / \mathrm{l}$ considered to indicate diabetic conditions. Insulin was not administered to the animals. The rats were housed in a controlled environment at $20-25^{\circ} \mathrm{C}$ with a $12 \mathrm{~h} \mathrm{light/dark} \mathrm{cycle,} \mathrm{and} \mathrm{were} \mathrm{provided} \mathrm{with} \mathrm{ad} \mathrm{libitum}$ access to food and water. All the animals were maintained and handled in accordance with the guidelines of the Association for Research in Vision and Ophthalmology statement for the Use of Animals in Ophthalmic and Vision Research (7). The present study was approved by the Animal Protection and Ethics Committee of Sichuan University (Chengdu, China).

Measurement of retinal function using flash-electroretinography $(F-E R G)$. Following dark adaptation for $60 \mathrm{~min}$ in a box, six rats from either the experimental group $(n=30)$ or control group $(n=30)$ received intraperitoneal injections of chloral hydrate solution (Junrui Biological Technology Co., Ltd.) at a concentration of $0.3 \mathrm{ml} / 100 \mathrm{~g}$ bodyweight, and had their pupils fully dilated with compound tropicamide eye-drops prior to assessment. Lidocaine hydrochloride (2\%; Shanghai Fosun Zhaohui Pharmaceutical Co., Ltd., Shanghai, China) was applied to the animals for retinal surface anesthesia. The cornea-touch electrode, reference electrode and grounding electrode were placed at the corneal margin of the eye, forehead and end of the tail under the skin, respectively.

The stimulator used was a Ganzfeld full-field (SG-2002; LKC Technologies, Inc. Gaithersburg, MD, USA) dome stimulator, as recommended by the standard F-ERG guidelines provided by the International Society for Clinical Electrophysiology of Vision (ISCEV) in 2004 (8). The stimulus intensity of the standard flash was $2.448 \mathrm{cdxs} / \mathrm{m}^{2}$. F-ERG retinal function was assessed using a visual electrophysiological system (MEB9200; Nihon Kohden, Tokyo, Japan). The amplitude and implicit duration of each wave form were analyzed.

Sample collection, RNA extraction and quality analysis. After 16 weeks, the rats were anesthetized with $10 \%$ chloral hydrate at a dose of $0.3 \mathrm{ml} / 100 \mathrm{~g}$ bodyweight by intraperitoneal injection. The rats were then sacrificed by overdose with $10 \%$ chloral hydrate following the removal of the eyes. Each retina was immediately dissected from the eye under a dissecting microscope (model SX-4; Guangzhou Ming-Mei Technology Co., Ltd., Guangzhou, China). These samples were then frozen in liquid nitrogen (Sichuan Qiaoyuan Gas Co., Ltd., Sichuan, China) and stored at $-80^{\circ} \mathrm{C}$. Microsurgical scissors were used to section the eye along the corneoscleral limbus. The retinas were then immediately dissected from the eye using the SX-4 dissecting microscope. The retinas of the rats were placed into a nuclease-free frozen storage tube prior to being frozen in liquid nitrogen overnight and stored at $-80^{\circ} \mathrm{C}$. The rat retinas were then placed into a nuclease-free
Table I. List of primers used in reverse transcription-quantitative polymerase chain reaction analysis.

\begin{tabular}{|c|c|}
\hline Gene & Primer sequence $\left(5^{\prime}-3^{\prime}\right)$ \\
\hline Cryaa & $\begin{array}{l}\text { F: CAGAGGGCTGAGGATTTGAG } \\
\text { R: ATGCCATCATTCCCTCTGAC }\end{array}$ \\
\hline Cryab & $\begin{array}{l}\text { F: CTGGGAGACGTGATTGAGGT } \\
\text { R: TCCGGTACTTCCTGTGGAAC }\end{array}$ \\
\hline Htra2 & $\begin{array}{l}\text { F: CAGCTGTGGATCCTGTAGCA } \\
\text { R: CTGAGCAGAGCTGACAATGC }\end{array}$ \\
\hline Pitx3 & $\begin{array}{l}\text { F: CGCCTCCTCCCCTTATGTAT } \\
\text { R: GCGTACTGGCAGGGACTAAG }\end{array}$ \\
\hline Fgf2 & $\begin{array}{l}\text { F: GGCTGCTGGCTTCTAAGTGT } \\
\text { R: CCGTTTTGGATCCGAGTTTA }\end{array}$ \\
\hline Casp3 & $\begin{array}{l}\text { F: GGACCTGTGGACCTGAAAAA } \\
\text { R: GCATGCCATATCATCGTCAG }\end{array}$ \\
\hline Stat3 & $\begin{array}{l}\text { F: TGATGCGCTCTTATGTGAGG } \\
\text { R: GGCGGACAGAACATAGGTGT }\end{array}$ \\
\hline Fabp7 & $\begin{array}{l}\text { F: CCAGCTGGGAGAAGAGTTTG } \\
\text { R: TTTCTTTGCCATCCCACTTC }\end{array}$ \\
\hline Jak3 & $\begin{array}{l}\text { F: CAGAACTCACAACCCCAGGT } \\
\text { R:GACAGGAGAGCAAGGGACTG }\end{array}$ \\
\hline Xiap & $\begin{array}{l}\text { F: GACAAATGTCCCATGTGCTG } \\
\text { R: CTAATGGACTGCGATGCTGA }\end{array}$ \\
\hline Gapdh & $\begin{array}{l}\text { F: AGACAGCCGCATCTTCTTGT } \\
\text { R: TGATGGCAACAATGTCCACT }\end{array}$ \\
\hline
\end{tabular}

F, forward; R, reverse.

microcentrifuge tube with plastic grinding rods. Retinal RNA was extracted using $1 \mathrm{ml}$ TRIzol reagent (Invitrogen; Thermo Fisher Scientific, Waltham, MA, USA) and quantified at an absorbance of $260 \mathrm{~nm}$ using an ultraviolet-visible (UV-Vis) spectrophotometer (NanoDrop 8000; Thermo Fisher Scientific, Inc.). Its integrity was determined using an Agilent 2100 Bioanalyzer (G2939AA; Agilent Technologies, Santa Clara, CA, USA).

Library preparation. The total RNA samples were first treated with DNase I (New England Biolabs, Inc., Ipswich, MA, USA) to degrade any possible DNA contamination, and the digestion products were then purified with magnetic beads (Dynabeads ${ }^{\circledR}$ mRNA Purification kit; Invitrogen; Thermo Fisher Scientific, Inc.). Subsequently, the mRNA was enriched using oligo (dT) magnetic beads (for eukaryotes; Dynabeads ${ }^{\circledR}$ mRNA Purification kit). The mRNA was then mixed with fragmentation buffer (Ambion ${ }^{\circledR}$ RNA Fragmentation Reagents; Ambion; Thermo Fisher Scientific, Inc.) and fragmented into short fragments ( 200 bp). The first strand of cDNA was then synthesized using random hexamer-primed reverse transcription (Super Script ${ }^{\circledR}$ II Reverse Transcriptase; Invitrogen; Thermo Fisher Scientific, Inc.) according to the manufacturer's protocol. Second strand buffer (Invitrogen; Thermo Fisher Scientific, Inc.), 
Table II. Rat blood glucose levels and weights.

\begin{tabular}{lccc}
\hline Parameter & Control & Diabetes & P-value \\
\hline Blood glucose $(\mathrm{mmol} / \mathrm{l})$ & $5.408 \pm 0.957$ & $29.215 \pm 4.474$ & $<0.001^{\mathrm{a}}$ \\
Weight $(\mathrm{g})$ & $332.538 \pm 34.391$ & $241.077 \pm 46.232$ & $<0.001^{\text {a }}$ \\
\hline
\end{tabular}

Data are expressed as the mean \pm standard deviation. ${ }^{\mathrm{a}} \mathrm{P}<0.05$ (independent $\mathrm{t}$-test).

deoxynucleotide triphosphates (New England Biolabs, Inc.), RNase H (Second Strand Master Mix; Invitrogen; Thermo Fisher Scientific, Inc.) and DNA polymerase I (Second Strand Master Mix; Invitrogen; Thermo Fisher Scientific, Inc.) were added to synthesize the second strand. The double strand cDNA was then purified with magnetic beads. End reparation was then performed, and the adaptors were then ligated to the ends of the fragments using a ClaSeek Library Preparation kit (Thermo Fisher Scientific, Inc.) according to the manufacturer's protocol. The ligation products were selected by size and purified on a Tris-acetate-EDTA-agarose gel (Sigma-Aldrich). Finally, the fragments were enriched by polymerase chain reaction (PCR) amplification using Platinum ${ }^{\circledR}$ Pfx DNA Polymerase (Invitrogen; Thermo Fisher Scientific, Inc.) and GeneAmp ${ }^{\circledR}$ system 9700 (Applied Biosystems; Thermo Fisher Scientific, Inc.) according to the manufacturer's protocol. PCR products were purified with magnetic beads and dissolved in $50 \mu \mathrm{l}$ Epstein-Barr solution (Agencourt ${ }^{\circledR}$ AMPure ${ }^{\circledR}$ XP Beads-PCR Purification; Beckman Coulter, Inc., Brea, CA, USA). During the quality control step, an Agilent 2100 Bioanalyzer was used to qualify and quantify the sample library.

RNA sequencing. The library products were prepared for sequencing with an Ion Proton platform (Ion Torrent ${ }^{\mathrm{TM}}$; Thermo Fisher Scientific, Inc.). Data filtering was performed to obtain high-quality reads, and the clean reads were saved as '.bam' files and used as the original sequencing results. All the sequence reads were mapped to the reference genome sequences. The maximum number of mismatches allowed for the mapping was set at two.

The expression level for each gene was determined by the number of reads uniquely mapped to the specific gene, and by the total number of uniquely mapped reads in the sample. To determine the expression levels of various genes and compare them between samples, the variable read per kilobase of exon per million mapped reads (RPKM) method was used (9). The statistical significance of the differential expression of each gene was determined, according to the P-value. Fold-change (FC) differences between the control and diabetic groups of rats were calculated. The P-values were adjusted for multiplicity to control the false discovery rate (FDR). Differentially expressed genes (DEGs) were defined as those with an $\mid \mathrm{FCl}>2$ and FDR $<5 \%$.

Gene ontology $(G O)$ and pathway enrichment analysis of DEGs. GO enrichment analysis provides all the GO terms, which are significantly enriched among DEGs, compared with the background genome, and filters the DEGs that correspond to biological functions (10). This method first maps all the DEGs to GO terms in the GO database (http://www.geneontology. org/) and calculates the numbers of genes for every term. It then uses a hypergeometric test to identify significantly enriched GO terms among the DEGs in relation to the background genome. Using non-redundant (NR) annotation, the Blast2GO version 3.0 program (Biobam, Valencia, Spain) was used to obtain GO annotations for the DEGs. Subsequently, WEGO software (http://wego.genomics.org.cn/cgi-bin/wego/index. pl) (11) was used to generate GO functional classifications for the DEGs and determine the distribution of gene functions of a species from the macro level.

Genes usually interact during certain biological functions, and a pathway-based analysis can assist in establishing the the biological functions of a gene (12). KEGG is a major public pathway-associated database (13). Pathway enrichment analysis identifies significantly enriched metabolic pathways and signal transduction pathways in DEGs, relative to the whole background genome.

Reverse transcription-quantitative PCR (RT-qPCR) validation of the RNA-seq data. To validate the RNA-seq findings in the present study, 10 genes, identified as differentially expressed, were randomly selected for RT-qPCR validation. The RT-qPCR was performed using eight samples of purified RNA, including four from the diabetes group and four from the control group. Total RNA was first reverse-transcribed into cDNA using a RevertAid First Strand cDNA Synthesis kit (Thermo Fisher Scientific, Inc.) according to the manufacturer's instructions. The primers were designed using Primer Express 3.0 (v. 0.4.0; http://bioinfo.ut.ee/primer3-0.4.0/) and the sequences are listed in Table I. GAPDH was used as a reference control. Subsequent qPCR was performed with a Mastercycler ${ }^{\circledR}$ ep realplex (Eppendorf, Germany) using SYBR Premix Ex Taq ${ }^{\mathrm{TM}}$ II (Takara Bio, Inc., Otsu, Japan) in accordance with the manufacturer's protocol. The qPCR was conducted with the following thermal cycling conditions: $95^{\circ} \mathrm{C}$ for $30 \mathrm{sec}$, followed by 40 cycles of $95^{\circ} \mathrm{C}$ for $5 \mathrm{sec}$ and $60^{\circ} \mathrm{C}$ for $30 \mathrm{sec}$, and three replicates were performed for each amplification. Relative quantification analyses were performed using the comparative $\mathrm{Cq}$ method, and relative gene expression levels were calculated using the $2^{-\Delta \Delta \mathrm{Cq}}$ method (14).

Statistical analysis. Independent sample t-tests were performed to assess for any significant differences in the measured variables between the control and diabetic groups. All values are reported as the mean \pm standard error of the mean, unless otherwise stated. Data were analyzed using Statistical Package 
Table III. Amplitudes of the flash-electroretinography waves.

\begin{tabular}{lccc}
\hline Wave & Control $(\mu \mathrm{V})$ & Diabetes $(\mu \mathrm{V})$ & P-value \\
\hline a-wave & $184.500 \pm 67.847$ & $94.600 \pm 40.357$ & $0.002^{\mathrm{a}}$ \\
b-wave & $366.400 \pm 79.120$ & $228.800 \pm 86.334$ & $0.002^{\mathrm{a}}$ \\
$\mathrm{OP}_{1}$ & $41.200 \pm 21.353$ & $16.800 \pm 8.284$ & $0.003^{\mathrm{a}}$ \\
$\mathrm{OP}_{2}$ & $51.600 \pm 26.667$ & $21.000 \pm 13.622$ & $0.005^{\mathrm{a}}$ \\
$\mathrm{OP}_{3}$ & $15.400 \pm 10.211$ & $11.000 \pm 8.446$ & 0.308 \\
$\Sigma \mathrm{OP}$ & $108.200 \pm 44.696$ & $48.800 \pm 26.080$ & $0.002^{\mathrm{a}}$ \\
\hline
\end{tabular}

Data are expressed as the mean \pm standard deviation. ${ }^{\mathrm{a}} \mathrm{P}<0.05$ (independent t-test). OP, oscillatory potential.

Table IV. Implicit durations of the flash-electroretinography waves.

\begin{tabular}{lccc}
\hline Wave & Control (ms) & Diabetes $(\mathrm{ms})$ & P-value \\
\hline a-wave & $22.440 \pm 2.029$ & $21.990 \pm 1.600$ & 0.589 \\
b-wave & $67.200 \pm 12.026$ & $99.420 \pm 17.328$ & $<0.001^{\mathrm{a}}$ \\
$\mathrm{OP}_{1}$ & $27.420 \pm 3.308$ & $27.390 \pm 3.206$ & 0.984 \\
$\mathrm{OP}_{2}$ & $37.260 \pm 2.952$ & $39.240 \pm 6.569$ & 0.396 \\
$\mathrm{OP}_{3}$ & $48.330 \pm 6.034$ & $51.470 \pm 7.181$ & 0.304 \\
$\sum \mathrm{OP}$ & $113.010 \pm 10.140$ & $118.800 \pm 16.380$ & 0.414 \\
\hline
\end{tabular}

Data are expressed as the mean \pm standard deviation. ${ }^{\mathrm{a}} \mathrm{P}<0.05$ (independent t-test). OP, oscillatory potential.

for the Social Sciences software, version 18.0 (SPSS, Inc., Chicago, IL, USA). $\mathrm{P}<0.05$ was considered to indicate a statistically significant difference.

\section{Results}

STZ induces diabetes. All the STZ-treated rats exhibited characteristics of diabetes, and their blood glucose levels were significantly higher, compared with those in the age-matched control rats. However, changes in weight occurred more slowly in the diabetic rats, compared with the age-matched control rats, following STZ treatment (Table II) and showed symptoms of polyuria. The age-matched control rats had normal glucose levels, showed no signs of polyuria and gained weight consistently until the animals were sacrificed.

F-ERG measurements. The ERG responses were defined according to the current ISCEV standards (15). The a-wave is a fast negative ERG component, obtained primarily from the maximal combined response. The leading edge reflects the membrane current in the photoreceptors. The a-wave amplitude is measured from the baseline to a-wave trough. The b-wave is a large positive ERG potential. Under scotopic conditions, the rising phase (up to the peak) is directly generated by bipolar cells and Müller cells. The implicit duration of the b-wave is measured from flash onset to the peak of the b-wave (16-18). The oscillatory potentials (OPs) are three to five low-amplitude, high-frequency wavelets, superimposed on the ascending limb of the ERG b-wave. The OPs are considered to result from feedback between the amacrine cells and bipolar cells, and/or feedback from ganglion cells to amacrine cells. The peak to trough amplitudes of the waves are frequently combined to provide an overall measure of the OP amplitude. Alternatively, the amplitudes of individual wavelets may be recorded. The latter may be preferable, as OPs are complex in origin, and individual wavelets may be generated at different sites within the retina $(19,20)$.

The amplitudes of the a-wave, b-wave, OP1, OP2 and $\Sigma$ OP were all significantly reduced (Table III) in the diabetic group, compared with the control group $(\mathrm{P}<0.05)$. Furthermore, the implicit $b$-wave durations in the diabetic group were significantly longer (Table IV) than those in the control group $(\mathrm{P}<0.001)$. No significant differences were found in the implicit durations of the a-wave, OP1, OP2, OP 3 or $\Sigma$ OP between the control and diabetic groups.

RNA-seq analysis and global gene expression profiles. To obtain triplicate results, three samples were obtained from the control and the diabetic groups of animals, with each sample obtained from a pair of rat retinas. In total, six RNA-Seq libraries were constructed, and over 14,000,000 clean reads were generated in each library. Subsequently, $\sim 87.9 \%$ of the total reads were mapped to the reference genome. The detailed mapping statistics are listed in Table V.

Gene expression levels and DEGs. The triplicate samples from the control and diabetic groups were assayed for DEGs (Fig. 1), and a total of 868 genes were found to be differentially expressed, with 565 upregulated genes and 303 downregulated genes. The 10 most markedly upregulated and downregulated genes are listed in Table VI.

GO categories and pathways. The GO classification comprises cellular component, molecular function and biological process domains. Based on sequence homology, the 868 DEGs identified in the present study were categorized into 49 functional groups. In the cellular component, molecular function and biological process GO classification categories, 26, 12 and 11 functional groups were identified, respectively (Fig. 2). Among these groups, the cellular process, cell and cell parts, and binding were the predominant in each of the three categories. A high percentage of the altered genes in the biological processes in the DEGs were involved in response to stimulus (349/ 637 genes; 54.8\%), regulation of biological processes (331/637 genes; 52.0\%) and metabolic processes (331/637 genes; 52.0\%). Furthermore, 94 apoptotic and apoptotic regulatory genes, and 19 inflammatory genes, were also detected as having changed.

The KEGG pathway significant enrichment analysis revealed that the DEGs were involved in 217 pathways, including CAMs, complement and coagulation cascades, and antigen processing and presentation.

Confirmation of DEGs using RT-qPCR. To validate the RNA-seq findings, the present study prepared rat retinas from separate groups of rats in each group qPCR analysis. In total, 10 genes were selected, comprising Gryaa, Gryab, Htra2, 


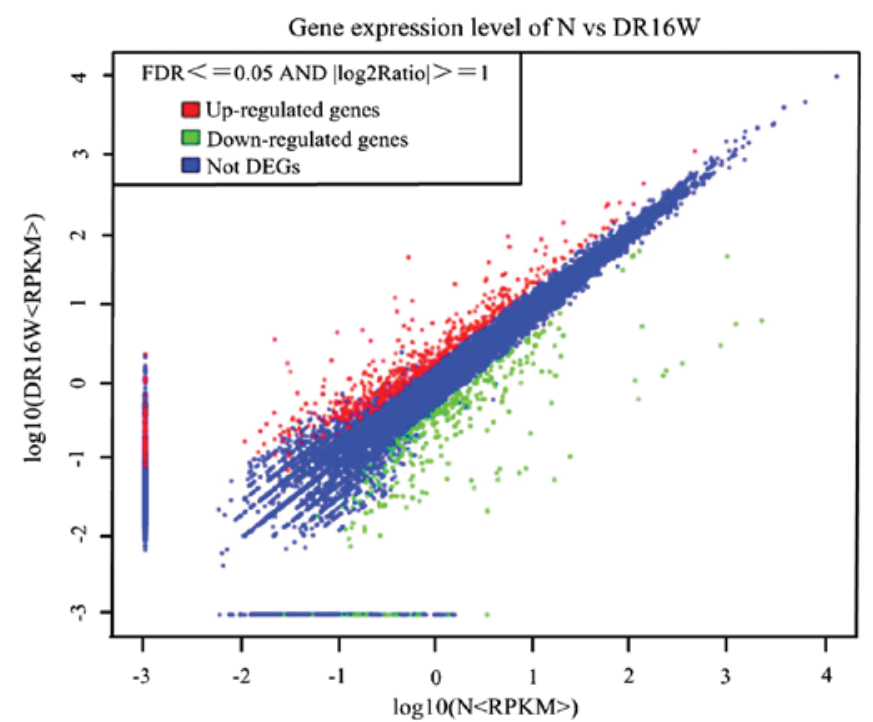

Figure 1. Waveforms of the a-wave, b-wave and OPs in flash-electroretinography examination of the control and diabetic groups. OP, oscillatory potential; DEGs, differentially expressed genes; FDR, false discovery rate.

Pitx3, Fgf2, Casp3, Stat3, Fabp7, Jak3, Xiap and Gapdh. Changes in the expression levels of these genes were determined using RT-qPCR. These results were similar to those obtained following the RNA-seq.

\section{Discussion}

In the present study, diabetes was induced chemically in 10 -week-old male Sprague-Dawley rats using STZ. All the STZ-treated rats exhibited characteristics of diabetes, including hyperglycemia, weight loss and polyuria. Furthermore, varying degrees of cataracts were prevalent among the diabetic rats. However, cataracts were not present in the age-matched control rats. The present study examined F-ERG following dark adaptation to evaluate the visual function of the control rats and diabetes-induced rats after 16 weeks. F-ERG is a widely used ocular electrophysiological assessment, and is considered an objective method for evaluating retinal function. The maximal amplitudes of the a- and b-waves were used as indicators for photoreceptor function and inner nuclear layer functional integrity, respectively. The sums of the OPs were used to assess the function of the inner retina $(16,17,19)$. Previous studies have found significant a-wave changes 10-12 weeks following STZ induction, which were not observed prior to this period (21-23), and 33\% b-wave loss at 12 weeks post-STZ injection (24). It has been reported that OPs are more affected by diabetes, compared with a-waves or b-waves, which are more attenuated and are affected earlier than the outer retinal responses $(25,26)$. Other studies have found that OPs are affected $<5$ weeks following the induction of diabetes by STZ $(24,27)$. These results are consistent with our finding that the a-wave, b-wave, OP1, OP2 and $\Sigma O P$ amplitudes were significantly reduced 16 weeks following STZ induction in the diabetic rats, compared with the control group $(\mathrm{P}<0.05)$. Furthermore, the implicit $\mathrm{b}$-wave durations in the diabetic rats were significantly longer, compared with those of the control group $(\mathrm{P}<0.001)$. Therefore, it was concluded that the inner and outer retinas 16 weeks following the onset of 
ํำ

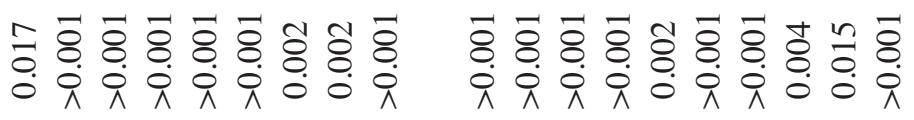

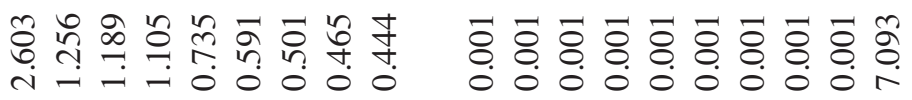

$=000$ a

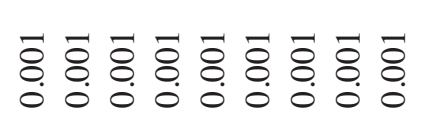

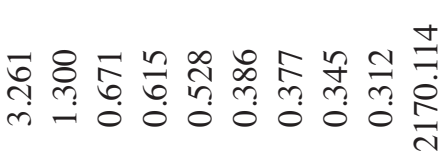

$\varangle \quad 0 \quad 0$ 安

匹

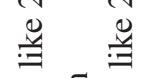

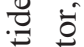

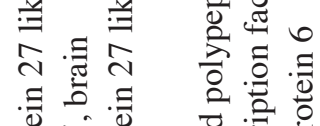

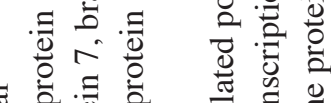

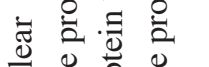

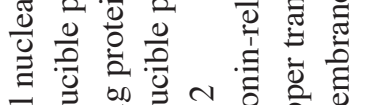

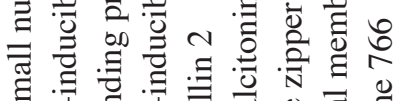

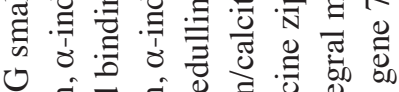
记

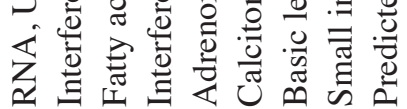

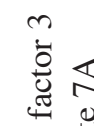
$\frac{\sqrt{5}}{\frac{0}{4}}$

.ํㅠㅁำ

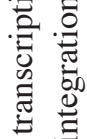

ن

胥

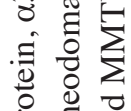

픙

원

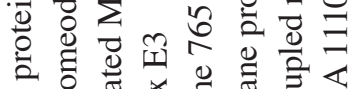

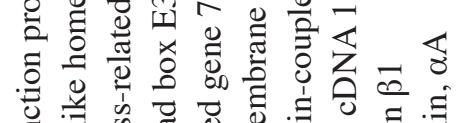

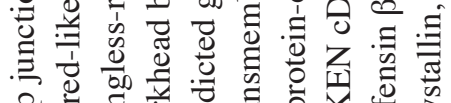

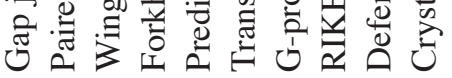

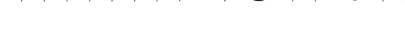

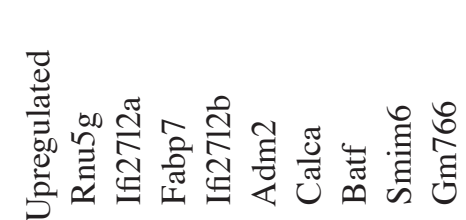

总

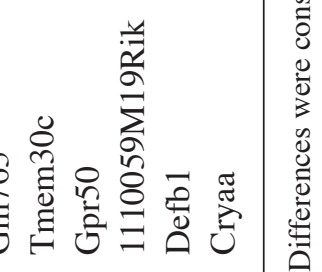




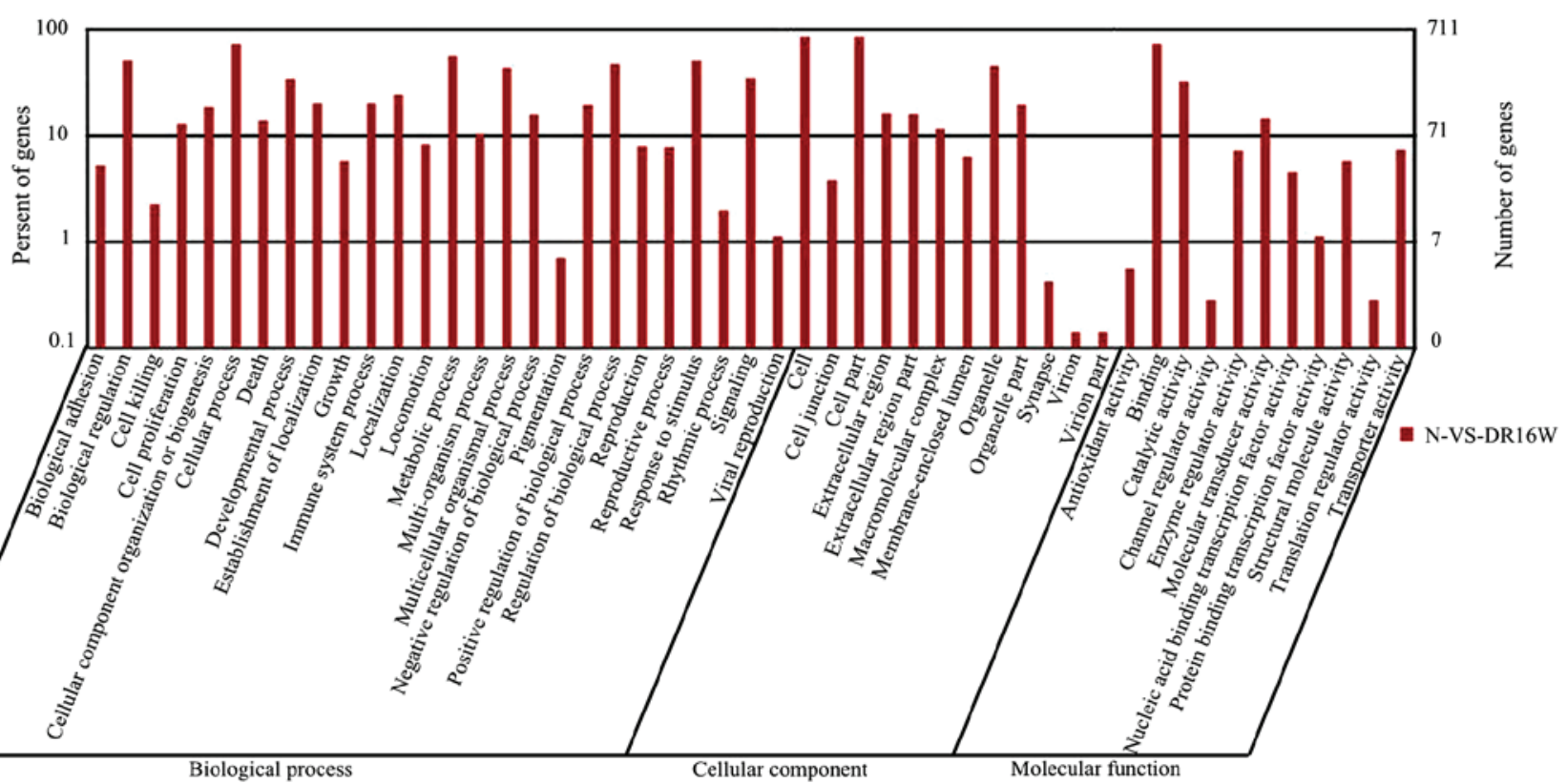

Figure 2. Scatter plot comparing the results of the log-transformed gene expression levels and differentially expressed gene distributions between the diabetic and normal control retinal samples.

STZ-induced diabetes were damaged by the high concentration of glucose in the blood.

The RNA-seq methodology allows for accurate and quantitative identification of molecular signatures. In the present study, 10 transcripts were verified using RT-qPCR. Changes were observed in a variety of retinal transcripts as a result of diabetes, and these can be used in determining the molecular signatures, which involve representative transcripts of the retina.

The 10 most upregulated and downregulated genes were identified in the present study. Interferon $\alpha$-inducible protein 27-like 2A (Ifi2712a) and interferon $\alpha$-inducible protein 27-like 2B (Ifi2712b), also termed interferon stimulated gene 12 (ISG12)a and ISG12b, respectively, belong to the ISG12 subfamily of ISGs. These genes are poorly characterized, and their physiological functions remain to be elucidated. However, studies have found that ISG12 inactivates the vasculoprotective functions of NR4A nuclear receptors (28). Fatty acid binding proteins (FABPs) are expressed in the majority of tissues, and they are suggested to act as central regulators of lipid metabolism, inflammation and energy homeostasis (29). FABP7, also termed brain FABP or BLBP, is widely used as a radial glial cell marker, and its expression is induced in astrocytes and Müller glial cells in rats subjected to kainate acid treatment, which leads to neuronal degeneration in the retina (30). Calcitonin-related peptide $\alpha$ (CALCA), also known as calcitonin gene-related peptide (CGRP), is a 37-amino-acid vasoactive neuropeptide. Adrenomedullin 2 (ADM2) or intermedin (IMD) is a member of the CGRP family $(31,32)$. CALCA is a potent vasodilator; thus, it possesses protective mechanisms, which are important for physiological and pathological conditions involving the cardiovascular system and wound healing (33). The upregulation of CALCA in the retina protects against cell apoptosis induced by the stress of acute myocardial infarction (34). Basic leucine zipper transcription factor ATF-like (Batf), which is a subgroup of the larger family of basic leucine zipper (bZIP) transcription factors, includes important positive transcriptional regulators in the immune system (35).

Paired-like homeodomain 3 (Pitx3) is a homeodomain-containing transcription factor and is crucial for the development and differentiation of dopamine (DA) neurons. Pitx3 can upregulate the expression levels of brain-derived neurotrophic factor (BDNF) and glial cell line-derived neurotrophic factor (GDNF) in the SH-SY5Y neuroblastoma cell line and in primary ventral mesencephalon (VM) cultures (36). Investigations of Pitx3-deficiency in aphakia mice have revealed that Pitx3 is required for the development of DA neurons in SNc (37,38). Studies have shown that Pitx3 directly regulates forkhead box E3 (Foxe3), a lens-specific transcription factor that is active during early lens development (39). Wnt signaling is essential for neuronal development and in developing nervous system maintenance. Modulation of the Wnt pathway has been reported to be a likely intervention target for DR (40). G protein-coupled receptor 50 (GPR50) is likely to be involved in the stress response and energy homeostasis in the mouse brain through neurotransmitter signaling (41).

Under control conditions in the present study, Ifi2712a, Ifi2712b, FABP7, CALCA, ADM2, and Batf were expressed at low levels, however they were markedly upregulated in the diabetic rats. By contrast, Pitx3, Foxe3, Gja3, GPR50 showed the opposite effects. These genes are involved in vasculoprotection, neuronal degeneration, cell apoptosis and immune function, and represent an important pool of candidate genes for future analysis (28-34,36-39,41).

Crystallins have been primarily characterized in the lens, have been shown to be critical in maintaining lens transparency, and may be involved in different cell and tissue functions in normal and diseased conditions in various tissues (42-44). These proteins are primarily categorized into two distinct families: $\alpha$ - and $\beta / \gamma$-crystallins. The two $\alpha$-crystallins, $\alpha \mathrm{A}$ and $\alpha \mathrm{B}$, are small heat-shock proteins, which act as molecular 
chaperones and are involved in the regulation of apoptosis (45). The function of $\beta / \gamma$-crystallin remains to be fully elucidated, however, the expression of $\beta / \gamma$-crystallins in the retina suggests that they may also function as stress proteins. $\alpha \mathrm{A}$ and $\alpha \mathrm{B}$-crystallin, which can protect retinal neurons from cell death (46), show increased expression in the early stages of the disease and decreased expression as the disease progresses. In the present study, it was found that the expression levels of $\alpha \mathrm{A}$ and $\alpha \mathrm{B}$ crystallins were downregulated 12 weeks following STZ induction, and the inconsistency in these findings with those of other reports (47-49) may be due to different durations of hyperglycemia, different species and/or different strains of animals. The expression of crystallins is a dynamic process that is associated with the duration of hyperglycemia and the extent of the pathogenic condition (47,50).

There is an accumulating body of evidence indicating that inflammation (51-54) and neurodegeneration (55-57) are important in the pathogenesis of DR. The results of the present study revealed that diabetes led to the abnormal expression of 94 genes involved in apoptosis and the regulation of apoptosis, and 19 inflammatory genes. The results of the KEGG pathway significant enrichment analysis revealed enrichment of the CAMs, complement and coagulation cascades, and of antigen processing and presentation. CAMs are cell-surface proteins, which are involved in binding with other cells or the extracellular matrix (ECM), and the binding of CAMs to their receptors/ligands is important in the mediation of fundamental inflammatory and immune reactions (58). Other studies have suggested that CAMs are important markers of endothelial dysfunction and are important in the development of DR (59-61). Complement and coagulation cascades, and antigen processing and presentation are involved in innate immune responses, and the dysregulation of innate immunity is associated with an increased inflammatory response $(62,63)$.

In conclusion, the F-ERG results in the present study revealed that the inner and outer retinas were damaged by 16 weeks of hyperglycemia. RNA-seq technology revealed a change in the molecular signature of the retina, and provided novel insights into the molecular mechanisms underlying DR. These abnormally expressed genes have a pathogenic effect in DR. Further investigations are necessary to examine the roles of these genes in the progression of DR. Taken together, RNA-seq was identified as a technology offering potential in the identification of novel biomarkers and therapeutic targets for DR.

\section{Acknowledgements}

This study was supported by the Natural Science Foundation of Guangxi Zhuang Autonomous Region (grant no. 2012GXNSFBA053122).

\section{References}

1. Ali TK and El-Remessy AB: Diabetic retinopathy: Current management and experimental therapeutic targets. Pharmacotherapy 29: 182-192, 2009.

2. Tang J and Kern TS: Inflammation in diabetic retinopathy. Prog Retin Eye Res 30: 343-358, 2011.

3. Abcouwer SF and Gardner TW: Diabetic retinopathy: Loss of neuroretinal adaptation to the diabetic metabolic environment. Ann N Y Acad Sci 1311: 174-190, 2014.
4. Simó R, Hernández $C$ and the European Consortium for the Early Treatment of Diabetic Retinopathy (EUROCONDOR): Neurodegeneration is an early event in diabetic retinopathy: Therapeutic implications. Br J Ophthalmol 96: 1285-1290, 2012.

5. Melmed RN, Benitez CJ and Holt SJ: Intermediate cells of the pancreas. 3. Selective autophagy and destruction of beta-granules in intermediate cells of the rat pancreas induced by alloxan and streptozotocin. J Cell Sci 13: 297-315, 1973.

6. Montgomery SB, Sammeth M, Gutierrez-Arcelus M, Lach RP, Ingle C, Nisbett J, Guigo R and Dermitzakis ET: Transcriptome genetics using second generation sequencing in a Caucasian population. Nature 464: 773-777, 2010.

7. The Association for Research in Vision and Ophtalmology: Policies: Statement for the use of animals in ophtalmic and visual research. http://www.arvo.org/About_ARVO/Policies/ Statement_for_the_Use_of_Animals_in_Ophthalmic_and_ Visual_Research/. Accessed January 15,2013.

8. Marmor MF, Holder GE, Seeliger MW and Yamamoto S; International Society for Clinical Electrophysiology: Standard for clinical electroretinography (2004 update). Doc Ophthalmol 108: 107-114, 2004.

9. Mortazavi A, Williams BA, McCue K, Schaeffer L and Wold B: Mapping and quantifying mammalian transcriptomes by RNA-Seq. Nat Methods 5: 621-628, 2008.

10. Zheng Q and Wang XJ: GOEAST: A web-based software toolkit for Gene Ontology enrichment analysis. Nucleic Acids Res 36: W358-W363, 2008.

11. Ye J, Fang L, Zheng H, Zhang Y, Chen J, Zhang Z, Wang J, Li S, Li R, Bolund L and Wang J: WEGO: A web tool for plotting GO annotations. Nucleic Acids Res 34 (Web Server issue): W293-W297, 2006.

12. Al-Shahrour F, Arbiza L, Dopazo H, Huerta-Cepas J, Mínguez P, Montaner D and Dopazo J: From genes to functional classes in the study of biological systems. BMC Bioinformatics 8: 114, 2007.

13. Kanehisa M, Araki M, Goto S, Hattori M, Hirakawa M, Itoh M, Katayama T, Kawashima S, Okuda S, Tokimatsu T and Yamanishi Y: KEGG for linking genomes to life and the environment. Nucleic Acids Res 36 (Database issue): D480-D484, 2008.

14. Livak KJ and Schmittgen TD: Analysis of relative gene expression data using real-time quantitative PCR and the 2(-Delta Delta C(T)) method. Methods 25: 402-408, 2001.

15. Hood DC, Bach M, Brigell M, Keating D, Kondo M, Lyons JS, Marmor MF, McCulloch DL, Palmowski-Wolfe AM and the International Society For Clinical Electrophysiology of Vision: ISCEV standard for clinical multifocal electroretinography (mfERG) (2011 edition). Doc Ophthalmol 124: 1-13, 2012.

16. Robson JG and Frishman LJ: Photoreceptor and bipolar cell contributions to the cat electroretinogram: A kinetic model for the early part of the flash response. J Opt Soc Am A Opt Image Sci Vis 13: 613-622, 1996.

17. Hood DC and Birch DG: Beta wave of the scotopic (rod) electroretinogram as a measure of the activity of human on-bipolar cells. J Opt Soc Am A Opt Image Sci Vis 13: 623, 1996.

18. Kondo M: Animal models of human retinal and optic nerve diseases analysed using electroretinography. Nippon Ganka Gakkai Zasshi 114: 248-278, 2010 (In Japanese).

19. Heynen H, Wachtmeister $L$ and van Norren D: Origin of the oscillatory potentials in the primate retina. Vision Res 25: 1365-1373, 1985.

20. Hennekes R: Clinical electroretinography. Fortschr Ophthalmol 86: 146-150, 1989 (In German).

21. Phipps JA, Yee P, Fletcher EL and Vingrys AJ: Rod photoreceptor dysfunction in diabetes: Activation, deactivation and dark adaptation. Invest Ophthalmol Vis Sci 47: 3187-3194, 2006.

22. Phipps JA, Fletcher EL and Vingrys AJ: Paired-flash identification of rod and cone dysfunction in the diabetic rat. Invest Ophthalmol Vis Sci 45: 4592-4600, 2004.

23. Li Q, Zemel E, Miller B and Perlman I: Early retinal damage in experimental diabetes: Electroretinographical and morphological observations. Exp Eye Res 74: 615-625, 2002.

24. Hancock HA and Kraft TW: Oscillatory potential analysis and ERGs of normal and diabetic rats. Invest Ophthalmol Vis Sci 45: 1002-1008, 2004

25. Bui BV, Armitage JA, Tolcos M, Cooper ME and Vingrys AJ: ACE inhibition salvages the visual loss caused by diabetes. Diabetologia 46: 401-408, 2003.

26. Sakai H, Tani Y, Shirasawa E, Shirao Y and Kawasaki K: Development of electroretinographic alterations in streptozotocin-induced diabetes in rats. Ophthalmic Res 27: 57-63, 1995. 
27. Ramsey DJ, Ripps H and Qian H: An electrophysiological study of retinal function in the diabetic female rat. Invest Ophthalmol Vis Sci 47: 5116-5124, 2006.

28. Papac-Milicevic N, Breuss JM, Zaujec J, Ryban L, Plyushch T, Wagner GA, Fenzl S, Dremsek P, Cabaravdic M, Steiner M, et al: The interferon stimulated gene 12 inactivates vasculoprotective functions of NR4A nuclear receptors. Circ Res 110: e50-e63, 2012

29. Storch J and Thumser AE: Tissue-specific functions in the fatty acid-binding protein family. J Biol Chem 285: 32679-32683, 2010.

30. Chang ML, Wu CH, Jiang-Shieh YF, Shieh JY and Wen CY: Reactive changes of retinal astrocytes and Muller glial cells in kainate-induced neuroexcitotoxicity. J Anat 210: 54-65, 2007.

31. Takei Y, Hyodo S, Katafuchi T and Minamino N: Novel fish-derived adrenomedullin in mammals: Structure and possible function. Peptides 25: 1643-1656, 2004.

32. Roh J, Chang CL, Bhalla A, Klein C and Hsu SY: Intermedin is a calcitonin/calcitonin gene-related peptide family peptide acting through the calcitonin receptor-like receptor/receptor activity-modifying protein receptor complexes. J Biol Chem 279: 7264-7274, 2004

33. Russell FA, King R, Smillie SJ, Kodji X and Brain SD: Calcitonin gene-related peptide: Physiology and pathophysiology. Physiol Rev 94: 1099-1142, 2014.

34. Yang JH, Zhang YQ and Guo Z: Endogenous CGRP protects retinal cells against stress induced apoptosis in rats. Neurosci Lett 501: 83-85, 2011.

35. Murphy TL, Tussiwand R and Murphy KM: Specificity through cooperation: BATF-IRF interactions control immune-regulatory networks. Nat Rev Immunol 13: 499-509, 2013.

36. Yang D, Peng C, Li X, Fan X, Li L, Ming M, Chen S and Le W: Pitx3-transfected astrocytes secrete brain-derived neurotrophic factor and glial cell line-derived neurotrophic factor and protect dopamine neurons in mesencephalon cultures. J Neurosci Res 86 : 3393-3400, 2008.

37. Nunes I, Tovmasian LT, Silva RM, Burke RE and Goff SP: Pitx3 is required for development of substantia nigra dopaminergic neurons. Proc Natl Acad Sci USA 100: 4245-4250, 2003.

38. Hwang DY, Ardayfio P, Kang UJ, Semina EV and Kim KS Selective loss of dopaminergic neurons in the substantia nigra of Pitx3-deficient aphakia mice. Brain Res Mol Brain Res 114 123-131, 2003

39. Ahmad N, Aslam M, Muenster D, Horsch M, Khan MA, Carlsson P, Beckers J and Graw J: Pitx3 directly regulates Foxe3 during early lens development. Int J Dev Biol 57: 741-751, 2013.

40. Chen Y, Hu Y, Zhou T, Zhou KK, Mott R, Wu M, Boulton M Lyons TJ, Gao G and Ma JX: Activation of the Wnt pathway plays a pathogenic role in diabetic retinopathy in humans and animal models. Am J Pathol 175: 2676-2685, 2009.

41. Grunewald E, Tew KD, Porteous DJ and Thomson PA: Developmental expression of orphan $\mathrm{G}$ protein-coupled receptor 50 in the mouse brain. ACS Chem Neurosci 3: 459-472, 2012.

42. Smolich BD, Tarkington SK, Saha MS and Grainger RM: Xenopus gamma-crystallin gene-expression: Evidence that the gamma-crystallin gene family is transcribed in lens and nonlens tissues. Mol Cell Biol 14: 1355-1363, 1994.

43. Head MW Peter A and Clayton RM: Evidence for the extralenticular expression of members of the beta-crystallin gene family in the chick and a comparison with delta-crystallin during differentiation and transdifferentiation. Differentiation 48: 147-156, 1991.

44. Clayton RM, Jeanny JC, Bower DJ and Errington LH: The presence of extralenticular crystallins and its relationship with transdifferentiation to lens. Curr Top Dev Biol 20: 137-151, 1986.

45. Andley UP: Crystallins in the eye: Function and pathology. Prog Retin Eye Res 26: 78-98, 2007.

46. Losiewicz MK and Fort PE: Diabetes impairs the neuroprotective properties of retinal alpha-crystallins. Invest Ophthalmol Vis Sci 52: 5034-5042, 2011.
47. Heise EA, Marozas LM, Grafton SA, Green KM, Kirwin SJ and Fort PE: Strain-independent increases of crystallin proteins in the retina of type 1 diabetic rats. PLoS One 8: e82520, 2013.

48. Kandpal RP, Rajasimha HK, Brooks MJ, Nellissery J, Wan J, Qian J, Kern TS and Swaroop A: Transcriptome analysis using next generation sequencing reveals molecular signatures of diabetic retinopathy and efficacy of candidate drugs. Mol Vis 18: 1123-1146, 2012

49. Fort PE, Freeman WM, Losiewicz MK, Singh RS and Gardner TW: The retinal proteome in experimental diabetic retinopathy: Up-regulation of crystallins and reversal by systemic and periocular insulin. Mol Cell Proteomics 8: 767-779, 2009.

50. Yamamoto S, Yamashita A, Arakaki N, Nemoto H and Yamazaki T: Prevention of aberrant protein aggregation by anchoring the molecular chaperone $\alpha \mathrm{B}$-crystallin to the endoplasmic reticulum. Biochem Biophys Res Commun 455: 241-245, 2014.

51. Gologorsky D, Thanos A and Vavvas D: Therapeutic interventions against inflammatory and angiogenic mediators in proliferative diabetic retinopathy. Mediators Inflamm 2012: 629452, 2012.

52. Zhang W, Liu H, Rojas M, Caldwell RW and Caldwell RB: Anti-inflammatory therapy for diabetic retinopathy. Immunotherapy 3: 609-628, 2011.

53. King GL: The role of inflammatory cytokines in diabetes and its complications. J Periodontol 79: 1527-1534, 2008.

54. Adamis AP: Is diabetic retinopathy an inflammatory disease? $\mathrm{Br}$ J Ophthalmol 86: 363-365, 2002

55. Martin PM, Roon P, Van Ells TK, Ganapathy V and Smith SB: Death of retinal neurons in streptozotocin-induced diabetic mice. Invest Ophthalmol Vis Sci 45: 3330-3336, 2004.

56. Howell SJ, Mekhail MN, Azem R, Ward NL and Kern TS: Degeneration of retinal ganglion cells in diabetic dogs and mice: Relationship to glycemic control and retinal capillary degeneration. Mol Vis 19: 1413-1421, 2013.

57. Joussen AM, Poulaki V, Mitsiades N, Cai WY, Suzuma I, Pak J, Ju ST, Rook SL, Esser P, Mitsiades CS, et al: Suppression of Fas-FasL-induced endothelial cell apoptosis prevents diabetic blood-retinal barrier breakdown in a model of streptozotocin-induced diabetes. FASEB J 17: 76-78, 2003.

58. Golias C, Tsoutsi E, Matziridis A, Makridis P, Batistatou A and Charalabopoulos K: Review. Leukocyte and endothelial cell adhesion molecules in inflammation focusing on inflammatory heart disease. In Vivo 21: 757-769, 2007.

59. Ugurlu N, Gerceker S, Yülek F, Ugurlu B, Sarı C, Baran P and Çağil N: The levels of the circulating cellular adhesion molecules ICAM-1, VCAM-1 and endothelin-1 and the flow-mediated vasodilatation values in patients with type 1 diabetes mellitus with early-stage diabetic retinopathy. Intern Med 52: 2173-2178, 2013.

60. Adamiec J and Oficjalska-Mlynczak J: Contribution of selected cellular adhesion molecules and proinflammatory cytokines in the pathogenesis of proliferative diabetic retinopathy. Przegl Lek 64: 389-392, 2007 (In Polish).

61. Khalfaoui T, Lizard G, Beltaief O, Colin D, Ben Hamida J, Errais K, Ammous I, Zbiba W, Tounsi L, Zhioua R, et al: Immunohistochemical analysis of cellular adhesion molecules (ICAM-1, VCAM-1) and VEGF in fibrovascular membranes of patients with proliferative diabetic retinopathy: Preliminary study. Pathol Biol (Paris) 57: 513-517, 2009.

62. Graves DT and Kayal RA: Diabetic complications and dysregulated innate immunity. Front Biosci 13: 1227-1239, 2008

63. Asnaghi V, Gerhardinger C, Hoehn T, Adeboje A and Lorenzi M: A role for the polyol pathway in the early neuroretinal apoptosis and glial changes induced by diabetes in the rat. Diabetes 52 . 506-511, 2003. 